\title{
ANÁLISE MACROMORFOLÓGICA DA COBERTURA PEDOLÓGICA E PERFIL DA TOPOSSEQUÊNCIA REALIZADA EM UM SEGMENTO DA VERTENTE DA FEI/UEM
}

\author{
Felipe Gomes Rubira $^{(\mathrm{a})}$, Archimedes Perez Filho ${ }^{(\mathrm{b})}$, Georgea do Vale de Melo ${ }^{(\mathrm{c})}$ \\ (a) Departamento de Geografia/Instituto de Geociências, UNICAMP, felipe_rubira@ @otmail.com \\ (b) Departamento de Geografia/Instituto de Geociências, UNICAMP, archi@ige.unicamp.br \\ (c) Departamento de Geografia/Centro de Ciências Humanas, Letras e Artes, UEM, georgea.melo@ hotmail.com
}

\section{EIXO: SISTEMAS GEOMORFOLÓGICOS: ESTRUTURA, DINÂMICA E PROCESSOS}

\begin{abstract}
Resumo
Esta pesquisa objetivou realizar a caracterização macromorfológica da cobertura pedológica de uma topossequência na FEI/UEM. A metodologia utilizada se baseou no manual de descrição e coleta de solo no campo da EMBRAPA (2005). Concluiu-se por meio dos resultados que a vertente em questão representa um sistema pedológico em transformação, possivelmente associado às ações dos fluxos hídricos verticais predominantes na organização da cobertura pedológica na alta e média vertente e dos fluxos laterais mais atuantes na média baixa e baixa vertente. Observou-se a transformação do horizonte latossólico em argílico, iniciando-se na base da vertente e avançando para o topo da mesma, originando o início de ligeira concavidade, elaborando degraus arenosos, principalmente relativos ao horizonte $\mathrm{A} \mathrm{e} \mathrm{E}$ do Argissolo. Estas ondulações nos horizontes possivelmente estão associadas às atividades geoquímicas e a uma provável alteração no nível de base local do ribeirão Centenário, capaz de acelerar os fluxos internos das soluções na vertente.
\end{abstract}

Palavras chave: Análise macromorfológica; Topossequência pedológica; Morfologia da vertente.

\section{Introdução}

Queiroz Neto (2011) em revisão conceitual evidencia a relação entre a pedologia e a geomorfologia, ciências interdependentes, com comprovada importância entre ambas a partir de trabalhos científicos como o de Milne (1935), Jenny (1941), Tricart (1968) e Espindola (2010). Em tempos pretéritos os estudos das duas ciências eram realizados de maneira fragmentada, não existia até então pesquisas interdisciplinares, que pudessem evidenciar a interdependência entre ambas por meio de uma abordagem sistêmica, que fosse capaz de revelar as relações da influência do relevo na formação dos horizontes dos solos ou de correlacionar processos pedogenéticos com modificações morfológicas do relevo.

Os estudos eram setorizados e havia principalmente por parte dos geomorfólogos a resistência de envolver a pedologia nos estudos morfodinâmicos da paisagem. Os solos eram apenas mencionados, sem maiores discussões sobre as relações que mantinham com o relevo. Esse panorama persistiu até a obra de Milne em 1935, considerada um marco para a aproximação entre as duas ciências. Por meio de Milne (1935) os 
estudos pedológicos foram aos poucos abandonando a visão estritamente verticalista, considerando a influência do relevo na formação dos solos, aproximando a ciência geomorfológica da pedológica, rompendo com a visão simplista da verticalidade. Milne (1935) introduz o conceito de catena e a concepção de lateralidade e, Boulet et al. (1982) elaboram o conceito topossequência. A partir deste momento as análises começaram a ser realizadas em sucessões contínuas nas vertentes, as quais trouxeram resultados que evidenciaram que a análise detalhada da organização lateral da cobertura pedológica é essencial para que se compreenda a gênese e a dinâmica da mesma. Os fluxos hídricos laterais e verticais também fornecem apontamentos para que a oposição entre pedologia e geomorfologia, pedogênese e morfogênese, se encerre definitivamente. Queiroz Neto (2011) afirma que a ação da água internamente e superficialmente exerce influência na formação dos solos e no modelado do relevo. Para o autor, internamente a ação da água acarreta a migração, transporte e exportação de elementos, interferindo diretamente na pedogênese. Superficialmente, a ação da água por meio do deflúvio exerce ação direta na morfogênese, promovendo o surgimento de feições erosivas. Nesta perspectiva, o presente trabalho tem por objetivo realizar a caracterização macromorfológica da cobertura pedológica ao longo da topossequência realizada em um segmento da vertente da Fazenda Experimental de Iguatemi da Universidade Estadual de Maringá (FEI/UEM). Simultaneamente, objetiva-se a partir do levantamento da topossequência, por meio da abertura de trincheiras e sondagens de solo, identificar e caracterizar as passagens dos horizontes pedológicos no perfil topográfico, descrevendo as possíveis transformações verificadas ao longo da vertente da FEI/UEM, na tentativa de caracterizar a dinâmica da vertente a partir da evolução do perfil.

Desta maneira, este trabalho justifica-se, pois, busca evidenciar a superação verticalista apontada por Queiroz Neto (2011), por meio da análise macromorfológica da cobertura pedológica, fundamental para a compreensão da distribuição espacial dos solos, de seus funcionamentos, gênese e de outras relações com outras disciplinas da natureza, permitindo a definição dos sistemas pedológicos em equilíbrio dinâmico ou em transformação. Ao mesmo tempo, esta pesquisa também busca a aproximação imprescindível para estudos sistêmicos, apontada por Tricart (1968), entre a ciência geomorfológica e pedológica, entre os processos morfogenéticos e pedogenéticos, entre a vertente e os solos.

\section{Localização e caracterização da área de estudo}

A área de estudo corresponde a uma encosta localizada na Fazenda Experimental de Iguatemi da Universidade Estadual de Maringá (FEI/UEM) que se localiza no distrito de Iguatemi, pertencente ao município de Maringá - PR (Figura1). A fazenda possui área de 170 hectares que foram adquiridos no fim 
da década de 1970 com o objetivo de servir como local de suporte para aulas práticas, estágios, desenvolvimento de pesquisas e extensão dos cursos de graduação e pós-graduação.

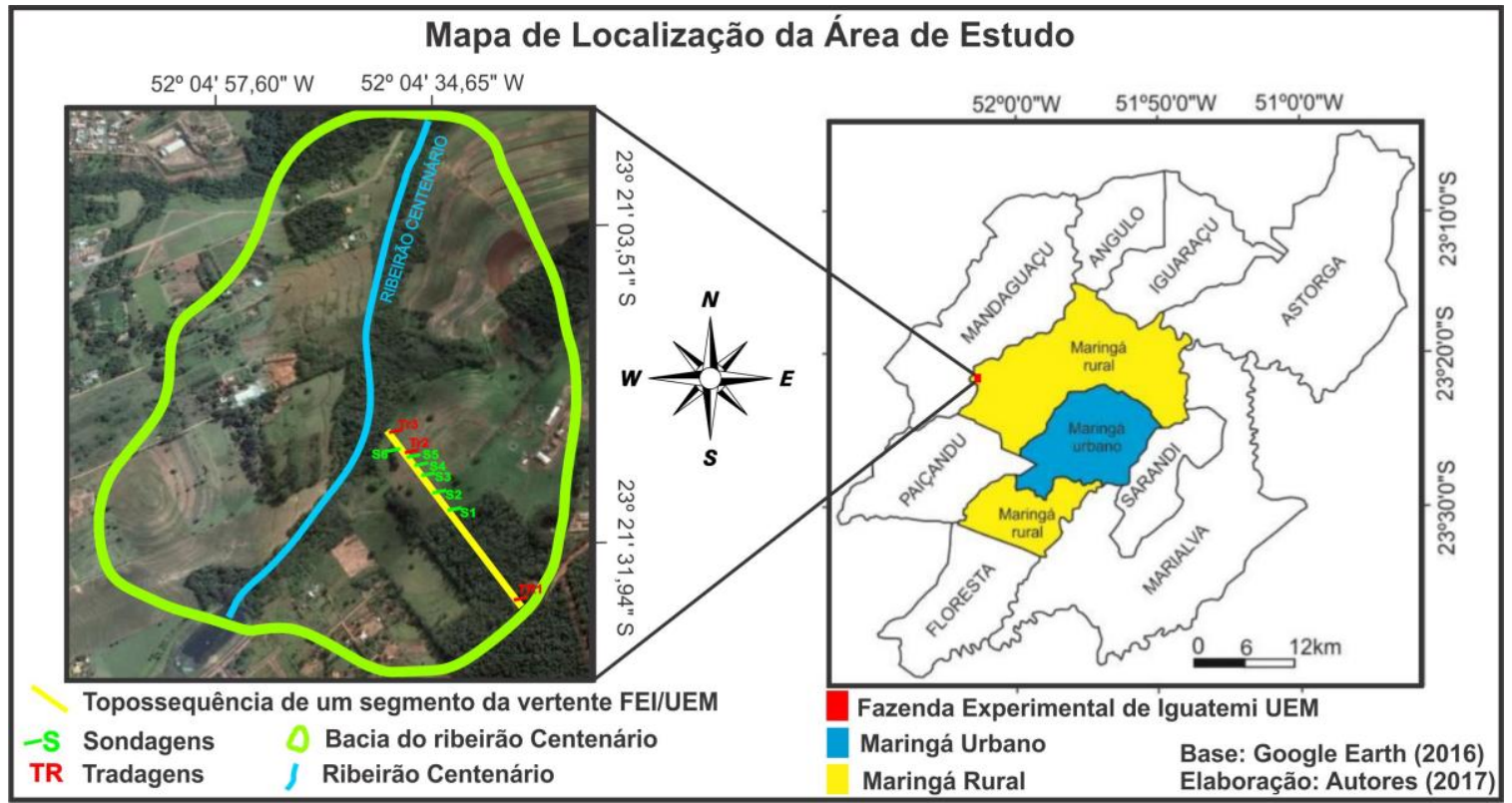

Figura 1: Mapa de localização da área de estudo

A área de estudo apresenta terrenos pertencentes à Formação Caiuá, que abrange uma extensão de aproximadamente $70.000 \mathrm{~km}^{2}$ na região noroeste do estado do Paraná. Os sedimentos que compõem a Formação Caiuá assentam-se de forma discordante sobre as rochas vulcânicas da Formação Serra Geral (BIGARELLA; MAZUCHOWSKI, 1985). A Formação Caiuá é constituída predominantemente de arenitos de frações média, fina a muito fina, com grãos de quartzo arredondados a bem arredondados e grau de seleção variando de pobre a muito bem selecionado, com pequenos teores de matriz lamítica na forma de níveis ou lentes (GASPARETTO; SOUZA, 2003).

O relevo que caracteriza a vertente analisada é constituído, por uma topografia suave ondulada. Os tipos de solos encontrados na área de estudo foram analisados durante os trabalhos de campo, constituindo-se em Latossolo Vermelho no topo até a média baixa vertente e Argissolo Vermelho na média baixa e baixa vertente. Próximos aos cursos d'água observou-se hidromorfismo.

\section{Metodologia}

Para a caracterização macromorfológica da cobertura pedológica de um segmento da vertente FEI/UEM, mostrou-se necessário adotar a metodologia de Análise da Cobertura Pedológica proposta pelo Manual de Descrição e Coleta de Solo no Campo, da Empresa Brasileira de Pesquisa Agropecuária - EMBRAPA (2005). 
Primeiramente foram abertas trincheiras, uma no topo a montante, e outras duas a jusante, uma na média baixa vertente e a outra na baixa vertente. A partir da abertura das trincheiras foi efetuado o processo de descrição das características macromorfológicas dos perfis de solos, que tiveram apoio no Manual de Descrição e Coleta de Solo no Campo da Empresa Brasileira da EMBRAPA (2005), os quais forneceram subsídios para as classificações.

Durante a descrição morfológica foram detalhadas respectivamente nesta ordem: a espessura do horizonte, cor seca e molhada do solo, textura, estrutura, porosidade, cerosidade, plasticidade, pegajosidade, presença de atividade biológica, feições pedológicas, mosqueamentos e zonas de transição em relação à cor, textura e estrutura de cada horizonte definido. As cores foram determinadas por meio da consulta ao livro das cores de Munsell (1981).

Depois das análises e classificações dos perfis de solo com a abertura das trincheiras, realizaram-se sondagens ao longo da vertente com o intuito de presenciar a possível influência do fluxo hídrico lateral, a partir de transformações entre horizontes de solo, as quais poderiam ser originadas pela ação da água superficial e subsuperficial. Para isso, as sondagens procuraram encontrar a passagem exata, vertical e lateral dos horizontes de solos. Foram realizadas seis sondagens com trado manual, que se iniciaram no topo da vertente e se prolongaram até a base da encosta, em pontos próximos ao ribeirão Centenário, efetuando assim, uma sucessão de pontos ao longo da mesma.

Os dados das sondagens (profundidade, espessura, textura, cor e transições de horizontes) foram plotados em um perfil topográfico e os limites contínuos encontrados em relação a estes dados foram ligados entre si. Se ocorria no esquema do perfil topográfico o aparecimento ou desaparecimento de horizontes, eram realizadas sondagens adicionais, até se conseguir estabelecer com o máximo de precisão a passagem lateral de um horizonte para o outro, o que constituía as transformações laterais.

A partir da análise destes pontos foi possível realizar suposições de como o fluxo hídrico age e influencia na formação e estruturação dos solos da vertente da FEI/UEM. Posteriormente, depois de todos os dados morfológicos coletados, do local exato da transição dos solos encontrados por meio do auxílio das trincheiras e tradagens, foi possível elaborar o perfil da topossequência realizada em campo com os detalhes da organização da cobertura pedológica da área em questão.

\section{Resultados e Discussões}

Inicialmente, antes de qualquer análise, cabe atentar o leitor para a mudança principalmente em relação à textura conforme descíamos a jusante, saindo do topo para base, as análises das transformações aqui representadas serão dispostas desta maneira. Outro ponto a ser destacado é que a área de estudo está relacionada a uma faixa de transição do Arenito Caiuá com o Basalto da formação Serra Geral. O Arenito 
acompanhou toda a topossequência realizada, este trabalho não se tornou uma topolitosequência justamente pelo fato de que nenhuma sondagem constatou a presença da rocha basáltica.

\subsection{Trincheiras}

Primeiramente, é válido observar pela Trincheira 1 - TR1 (Quadro 1), localizada na alta vertente, a diferença do solo se comparado aos da base da vertente (TR2, TR3). A formação pedológica deste ponto possui textura arenosa e, conforme se aprofunda, a porcentagem de argila se eleva, originando um solo com textura arenoargilosa a argiloarenosa. Este processo provavelmente está associado à lixiviação atuante no topo da vertente, evidência que corrobora com um provável predomínio do fluxo hídrico vertical neste compartimento da vertente.

A mudança de textura observada foi a principal responsável para a determinação da divisão do horizonte B (Bw1, Bw2), pois o Bw1 apresentou-se com textura mais arenosa se comparado com o Bw2 que possui textura ligeiramente argilosa.

Quadro 1: Classificações e descrições morfológicas do perfil de solo da TR2

\begin{tabular}{|c|c|c|c|}
\hline \multicolumn{4}{|c|}{$\begin{array}{c}\text { TRINCHEIRA 1 (TR1) } \\
23^{\circ} 21^{\prime} 37,01 " \mathrm{~S} / 52^{\circ} 04,27,78^{\prime} \text { "W } \\
\end{array}$} \\
\hline Ponto/ Horizonte & $\mathbf{A}$ & Bw1 & Bw2 \\
\hline Espessura & $0-22 \mathrm{~cm}$ & $22-120 \mathrm{~cm}$ & $120 \mathrm{~cm}+$ \\
\hline Cor $($ Seco) & 2,5 YR $4 / 4$ a $3 / 4$ & 2,5 YR $4 / 4$ a $3 / 4$ & 2,5 YR 5/4 \\
\hline Cor (Molhado) & 2,5 YR 3/4 - 3/3 (amassado) & $2,5 \mathrm{YR} 3 / 4$ & $2,5 \mathrm{YR} 5 / 3$ \\
\hline Textura & Arenosa & Arenoargilosa & Arenoargilosa a Argiloarenosa \\
\hline Estrutura & $\begin{array}{l}\text { Subangular, pequeno a médio, fraco } \\
\text { (até } 4 \mathrm{~mm} \text { ) }\end{array}$ & $\begin{array}{l}\text { Subangular, fraco, com tendência a } \\
\text { microagregado }\end{array}$ & $\begin{array}{l}\text { Subangular, pequeno a médio, com } \\
\text { tendência a microagregado }\end{array}$ \\
\hline Porosidade & Abundante $(1 \mathrm{~mm}$ a $3 \mathrm{~mm})$ & $\begin{array}{c}\text { Abundante } \\
\text { (intensa atividade biológica) }\end{array}$ & Abundante \\
\hline Cerosidade & Ausente & Ausente & Ausente \\
\hline Plasticidade & Não-plástico & Ligeiramente Plástico & Ligeiramente Plástico \\
\hline Pegajosidade & Não-pegajoso & Pouco pegajoso & Ligeiramente Pegajoso \\
\hline Atividade Biológica & $\begin{array}{l}\text { Abundante, raízes de até } 1 \mathrm{~cm}, \\
\text { pedotúbulos }\end{array}$ & $\begin{array}{l}\text { Raízes fasciculadas, microrganismos } \\
\text { abundantes, presença de fragmentos de } \\
\text { carvão (até } 2 \mathrm{~mm} \text { ) }\end{array}$ & $\begin{array}{l}\text { Muitas raízes até } 10 \mathrm{~mm} \text {, } \\
\text { pedotúbulos }\end{array}$ \\
\hline Feições Pedológicas & Migração de areia & $\begin{array}{c}\text { Argila de cor mais avermelhada entre } \\
\text { os agregados }\end{array}$ & Sem migração de areia \\
\hline Mosqueamento & - & - & - \\
\hline Transição & Difusa em relação à cor e estrutura & Difusa em relação à cor e estrutura & - \\
\hline
\end{tabular}

As transições do horizonte $\mathrm{A}$ para o $\mathrm{Bw} 1$ e do $\mathrm{Bw} 1$ para o Bw2 apresentaram-se difusa em relação à cor e a estrutura. A porosidade, resultantes da intensa atividade biológica presente no local apresentou-se abundante. A cerosidade foi classificada como nula devido à pequena presença de argila nos três 
horizontes. A plasticidade foi categorizada como não plástica no horizonte A e ligeiramente plástica no horizonte $\mathrm{B}$ (Bw1, Bw2) pelo fato do solo não possuir elevada acumulação de argila. A estrutura neste primeiro ponto manteve-se constante nos horizontes $\mathrm{A}, \mathrm{Bw} 1 \mathrm{e} \mathrm{Bw} 2$, apresentando-se subangular, fraca, com tendência a microagregado, caracterizando o solo dos horizontes em questão como um típico Latossolo Vermelho (Bw1 e Bw2).

Na Trincheira 2 - TR2 (Quadro 2), localizada na média baixa vertente, presenciou-se maior influência do fluxo hídrico lateral, pois, foi possível perceber uma nítida ondulação na transição dos horizontes, provavelmente associada a ação da água subsuperficial lateral. O solo caracterizado aqui é um Argissolo Vermelho, bem definido.

Quadro 2: Classificações e descrições morfológicas do perfil de solo da TR2

\begin{tabular}{|c|c|c|c|}
\hline \multicolumn{4}{|c|}{$\begin{array}{c}\text { TRINCHEIRA 2 (TR2) } \\
23^{\circ} 21^{\prime} 23,58 \text { " S / } 52^{\circ} 04,37,46^{\prime} \text { W } \\
\end{array}$} \\
\hline Ponto/ Horizonte & $\mathrm{E}$ & $\mathrm{Bt}$ & $\mathrm{C}$ \\
\hline Espessura & $15 / 20-28 \mathrm{~cm}$ & $28-80 \mathrm{~cm}$ & $80 \mathrm{~cm}+$ \\
\hline Cor (Seco) & 7,5 YR 5/4 & 2,5 YR $6 / 3$ a $5 / 3$ & $2,5 \mathrm{YR} 7 / 3$ \\
\hline Cor (Molhado) & $7,5 \mathrm{YR} 4 / 3$ & $2,5 \mathrm{YR} 4 / 4$ & $2,5 \mathrm{YR} 7 / 3$ \\
\hline Textura & Arenoargilosa & Argiloarenosa & Arenosa \\
\hline Estrutura & Angular, Média a Grande, firme & Angular, Média a Grande & $\begin{array}{c}\text { Maciça, não estruturada, grãos } \\
\text { empilhados }\end{array}$ \\
\hline Porosidade & Abundante & Abundante - pedotúbulos & Abundante \\
\hline Cerosidade & Ausente & Ausente & Ausente \\
\hline Plasticidade & Ausente & Ligeiramente Plástico & Não plástico \\
\hline Pegajosidade & Ligeiramente Pegajoso & Ligeiramente Pegajoso & Não pegajoso \\
\hline Atividade Biológica & $\begin{array}{c}\text { Raízes milimétricas a } 1 \mathrm{~cm} \text {, } \\
\text { pedotúbulos, microrganismos e } \\
\text { carvão }\end{array}$ & $\begin{array}{l}\text { Abundante, presença de raízes (até } \\
1 \mathrm{~cm}) \text {, carvão (mm), microrganismos }\end{array}$ & $\begin{array}{l}\text { Pedotúbulos de raízes, sem atividade } \\
\text { animal }\end{array}$ \\
\hline Feições Pedológicas & $\begin{array}{c}\text { Sem lavagem de areia/ acumulação } \\
\text { de argila }\end{array}$ & Migração de Areia & não existe (rocha) \\
\hline Mosqueamento & $\begin{array}{c}2,5 \text { YR 4/6 - Seco } \\
2,5 \text { YR 4/4 - Molhado }\end{array}$ & $\begin{array}{c}2,5 \text { YR 4/6 - Seco/ Úmido (10 a } \\
40 \mathrm{~mm})\end{array}$ & - \\
\hline Transição & Gradual em relação à textura e cor & $\begin{array}{l}\text { Gradual/ Ondulada (cor) Abrupta } \\
\text { (textura) }\end{array}$ & - \\
\hline
\end{tabular}

Os solos encontrados neste ponto da vertente são constituídos por uma textura arenoargilosa. O horizonte A neste local do perfil é ausente, isso porque a camada superficial encontrada caracterizou-se como um horizonte alterado, modificado pelo homem, transportado e colocado até ali. Portanto, ausente de características naturais, impossibilitando desta maneira a sua descrição morfológica, um horizonte ausente de estrutura. Esta camada de solo foi classificada como "Au", mas não foi descrita no quadro 2, justamente pelo fato do solo ter sido modificado por ações antrópicas. 
Abaixo do $\mathrm{Au}$, foi presenciado um horizonte de perda, in situ, classificado como E. Constitui-se em um horizonte com textura arenoargilosa e estrutura angular firme média a grande, sendo ligeiramente plástico e pegajoso. Também possui atividade biológica, com raízes de até $1 \mathrm{~cm}$ de diâmetro, sem lavagem de areia. Verificou-se mosqueamento, o que pode ser considerado uma evidencia da ação da água subsuperficial. Na faixa de transição do horizonte $\mathrm{Au}$ para o E foi observado um ondulamento, responsável por fazer com que alguns pontos do horizonte $\mathrm{E}$ se iniciassem aos $15 \mathrm{~cm}$ e em outros aos $20 \mathrm{~cm}$, ambos se encerrando na profundidade de $28 \mathrm{~cm}$.

$\mathrm{O}$ horizonte inferior ao E constituiu-se em um Bt, iniciou-se aos $28 \mathrm{~cm}$ e se encerrou aos $80 \mathrm{~cm}$ de profundidade, caracterizou-se por ser um horizonte de acumulação, a textura passou a ser arenoargilosa, comprovando uma pequena acumulação de argila. A transição do Horizonte $\mathrm{E}$ para com o horizonte $\mathrm{Bt}$ ocorreu de maneira gradual em relação à cor e a textura.

O horizonte $\mathrm{C}$, iniciou-se aos $80 \mathrm{~cm}$ de profundidade, é o horizonte que faz contato com o $\mathrm{Bt}$, sendo constituído pela rocha alterada, representada pelo arenito Caiuá, bem arenoso, de estrutura maciça com grãos empilhados e não estruturados. Durante a análise notou-se a porosidade abundante do horizonte e a ausência de pegajosidade e de plasticidade devido à predominância de areia. A transição do horizonte $\mathrm{Bt}$ para o C caracterizou-se como gradual e ondulada em relação à cor e abrupta em relação à textura.

Na Trincheira 3 - TR3 (Quadro 3), localizada na média baixa vertente, foi novamente encontrado o Argissolo Vermelho, bem definido em relação as alternâncias de cores do horizonte E para o Bt1 e Bt2, sendo o primeiro (E) um horizonte de perda e o B (Bt1 e Bt2) de acumulação de argila.

O horizonte superior, classificado como horizonte A, foi subdividido em A1 e Au devido a modificações antrópicas impostas à cobertura pedológica. O horizonte A1 apresentou-se como um horizonte A típico, com presença de matéria orgânica e cor mais escura, já o horizonte classificado como Au apresentou-se modificado, transportado pelo homem, com nítida diminuição de matéria orgânica e com cor mais acinzentada. Possivelmente, em tempos pretéritos houve um processo de aterramento no local de maneira superficial e posteriormente desenvolveu-se sobre o horizonte Au a camada superficial A1, composta por matéria orgânica. A transição deste horizonte Au para o inferior E, configurou-se como gradual em relação à textura e abrupta em relação à cor.

O horizonte E, típico em Argissolos, configura-se como um horizonte de perda, sua espessura corresponde as medidas de $50 \mathrm{~cm}$ a $70 \mathrm{~cm}$ de profundidade. Observou-se textura arenosa com menos porcentagem de areia que os superiores A (A1 e Au). A transição do horizonte E para o inferior Bt1 configurou-se como gradual em relação à cor e abrupta em relação à textura.

O horizonte inferior foi classificado como Bt1, iniciou-se aos $70 \mathrm{~cm}$ e se encerrou aos $103 \mathrm{~cm}$ de profundidade, um horizonte de acumulação. A textura passou a ser argiloarenosa, a estrutura permaneceu 


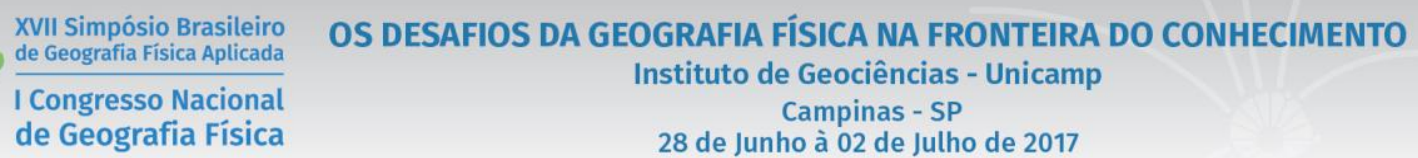

subangular com blocos pequenos a médios, com pouca cerosidade e porosidade comum. A transição do horizonte Bt1 para o Bt2 estabeleceu-se de maneira gradual em relação à textura e a cor.

Quadro 3: Classificações e descrições morfológicas do perfil de solo da TR3

\begin{tabular}{|c|c|c|c|c|c|}
\hline \multicolumn{6}{|c|}{$\begin{array}{c}\text { TRINCHEIRA 3 (TR3) } \\
23^{\circ} 21^{\prime} 21,50 " \text { S / } 52^{\circ} 04,30,09 \text { ' W }\end{array}$} \\
\hline Ponto/ Horizonte & $\mathrm{A} 1$ & $\mathrm{Au}$ & E & Bt1 & Bt2 \\
\hline Espessura & $0-13 \mathrm{~cm}$ & $13-50 \mathrm{~cm}$ & $50-70 \mathrm{~cm}$ & $70-103 \mathrm{~cm}$ & $103 \mathrm{~cm}+$ \\
\hline Cor (Seco) & 7,5 YR 4/4 & $5 \mathrm{YR} 4 / 4$ & 10 YR 6/2 & $10 \mathrm{YR} 5 / 3$ & $10 \mathrm{YR} 4 / 2$ \\
\hline Cor (Molhado) & 7,5 YR $2,5 / 3$ & $5 \mathrm{YR} 3 / 4$ & $10 \mathrm{YR} 4 / 2$ & $10 \mathrm{YR} 6 / 8$ & $10 \mathrm{YR} 3 / 2$ \\
\hline Textura & Francoarenosa & Francoarenosa & Arenosa & Argiloarenosa & Argilosa \\
\hline Estrutura & $\begin{array}{c}\text { Granular de } \\
\text { Microagregados }\end{array}$ & $\begin{array}{c}\text { Subangular com } \\
\text { tendência a formação } \\
\text { de microagregados }\end{array}$ & $\begin{array}{l}\text { Em blocos } \\
\text { subangulares }\end{array}$ & $\begin{array}{c}\text { Subangular com } \\
\text { blocos de pequenos a } \\
\text { médios }\end{array}$ & $\begin{array}{l}\text { Subangular firme } \\
\text { com blocos de } \\
\text { pequenos a médios }\end{array}$ \\
\hline Porosidade & Abundante & Abundante & Abundante & Comum & Comum \\
\hline Cerosidade & Ausente & Ausente & Ausente & Ausente & Ausente \\
\hline Plasticidade & Não Plástico & Não Plástico & Não Plástico & $\begin{array}{l}\text { Ligeiramente } \\
\text { plástico }\end{array}$ & $\begin{array}{l}\text { Ligeiramente } \\
\text { plástico }\end{array}$ \\
\hline Pegajosidade & Não Pegajoso & Não Pegajoso & Não pegajoso & $\begin{array}{l}\text { Ligeiramente } \\
\text { pegajoso }\end{array}$ & Pegajosidade alta \\
\hline Atividade Biológica & $\begin{array}{l}\text { Raízes de tamanho } \\
\text { variável, } \\
\text { pedotúbulos, } \\
\text { microrganismos }\end{array}$ & $\begin{array}{l}\text { Pouca presença de } \\
\text { raízes e } \\
\text { microrganismos }\end{array}$ & $\begin{array}{c}\text { Pedotúbulos de } \\
\text { raízes, sem atividade } \\
\text { animal }\end{array}$ & $\begin{array}{l}\text { Atividade biológica } \\
\text { abundante } \\
\text { (microraízes e } \\
\text { microfauna) }\end{array}$ & $\begin{array}{l}\text { Raízes em menor } \\
\text { quantidade, porém } \\
\text { ainda apresenta } \\
\text { pedotúbulos e } \\
\text { microfauna }\end{array}$ \\
\hline Feições Pedológicas & $\begin{array}{c}\text { Sem lavagem de } \\
\text { areia/ acumulação de } \\
\text { argila }\end{array}$ & $\begin{array}{l}\text { Sem lavagem de } \\
\text { areia }\end{array}$ & $\begin{array}{l}\text { Sem lavagem de } \\
\text { areia }\end{array}$ & $\begin{array}{l}\text { Sem lavagem de } \\
\text { areia }\end{array}$ & $\begin{array}{c}\text { Sem lavagem de } \\
\text { areia, sem nódulos e } \\
\text { concreções }\end{array}$ \\
\hline Mosqueamento & - & - & $\begin{array}{l}5 \text { YR 5/4 (seco) } \\
5 \text { YR 4/2 (úmido) }\end{array}$ & $\begin{array}{l}5 \text { YR 6/8 (seco) } \\
5 \text { YR 5/6 (úmido) }\end{array}$ & $\begin{array}{l}5 \text { YR 5/8 (seco) } \\
5 \text { YR 5/8 (úmido) }\end{array}$ \\
\hline Transição & $\begin{array}{l}\text { Difusa em relação à } \\
\text { textura e cor }\end{array}$ & $\begin{array}{l}\text { Gradual em relação à } \\
\text { textura Abrupta em } \\
\text { relação cor }\end{array}$ & $\begin{array}{l}\text { Gradual em relação à } \\
\text { cor } \\
\text { Abrupta em relação à } \\
\text { textura }\end{array}$ & $\begin{array}{l}\text { Gradual na textura e } \\
\text { na cor }\end{array}$ & - \\
\hline
\end{tabular}

O horizonte $\mathrm{Bt} 2$, com mais de $103 \mathrm{~cm}$ é como o anterior, um horizonte de acumulação, a porcentagem de argila neste ponto aumentou consideravelmente, influenciando até na mudança de cor, que se tornou mais escura. O claro aumento de argila constituiu-se como o principal responsável para que fosse realizada a subdivisão do horizonte Bt. A textura passou de argiloarenosa para argilosa, mesmo com o aumento significativo de argila a estrutura, porosidade e cerosidade mantiveram-se iguais ao horizonte anterior. A plasticidade permaneceu ligeiramente plástica e a pegajosidade tornou-se alta.

Quanto às feições pedológicas, neste horizonte foi perceptível a presença de nódulos e concreções ferruginosas, indicativo de ação de água subsuperficial, agindo tanto quimicamente como mecanicamente, trazendo finos das partes superiores e acumulando no sopé da encosta. Observou-se sinais de hidromorfismo. 


\subsection{Sondagens}

Apesar de ser realizada a abertura de três trincheiras, com posterior descrição dos perfis, não foi encontrado em nenhuma delas a passagem exata, a transição de um solo para o outro, do Latossolo Vermelho para o Argissolo Vermelho. Para conseguir estabelecer com o máximo de precisão o aparecimento ou desaparecimento dos horizontes lateralmente, ou seja, a localização do limite de contato entre eles foram realizadas seis sondagens (tradagens) ao longo da vertente, para que se tornasse possível elaborar corretamente o perfil da topossequência.

Na S1, S2, S3 e S4 (Figura 2), foi possível observar características muito próximas aos solos descritos na TR1, evidenciando a presença do Latossolo Vermelho. Da S1 a S4 verificou-se a tendência na homogeneização da textura, tanto vertical como lateral, não deparando com nenhuma mudança significativa do fluxo hídrico lateral até este ponto devido à ausência de mosqueamentos e ondulações, predominando possivelmente, a influência do fluxo hídrico vertical, verificado pela acumulação de argila. A S1 foi realizada no ponto médio da vertente, a 300m à jusante da TR1. A S2 foi realizada $100 \mathrm{~m}$ à jusante da $S 1$. A S3 foi realizada 30m a jusante da $S 2$. A $S 4$ foi realizada $31 \mathrm{~m}$ a jusante da $S 3$.

Verificou-se que os solos encontrados nessas quatro primeiras sondagens apresentaram textura arenosa com aumento da porcentagem argila nas maiores profundidades, caracterizando uma variação ao longo do perfil, de francoarenosa a argiloarenosa. Na S1 a mudança ocorreu entre $80 \mathrm{~cm}$ e $100 \mathrm{~cm}$ passando de arenosa a arenoargilosa para arenoargilosa. $\mathrm{Na}$ S2 a alteração ocorreu em $120 \mathrm{~cm}$ e $140 \mathrm{~cm}$ entre textura arenoargilosa a argiloarenosa. Na S3 de $100 \mathrm{~cm}$ a $120 \mathrm{~cm}$ tornou-se argiloarenosa e depois voltou a constituir-se como arenoargilosa, este fato foi ocasionado pela presença de lente de acumulação de argilas localizada neste ponto do perfil (Figura 2). Na S4 a mudança ocorreu entre $120 \mathrm{~cm}$ e $140 \mathrm{~cm}$ passando de arenosa para arenoargilosa.

Na S5 finalmente foi possível perceber o início das transformações laterais, uma nítida mudança se comparada com as quatro primeiras sondagens (S1, S2, S3, S4) e com a TR1. Neste ponto verificou-se que as características pedológicas dos horizontes alteraram-se, aproximando-se do solo analisado na TR2. Constatou-se, por meio desta sondagem, ondulações provavelmente associadas à influência de atuação dos fluxos hídricos subsuperficiais, que possivelmente influíram a transição do Argissolo Vermelho (E, Bt) para o Latossolo Vermelho (Bw) a partir de $200 \mathrm{~cm}$ de profundidade. Esta alteração foi interpretada como proveniente das modificações relacionadas à ação dos fluxos hídricos laterais subsuperficiais, apresentando-se responsáveis pela transformação do sistema pedológico em questão.

Portanto, até os $20 \mathrm{~cm}$ verificou-se horizonte A. De $20 \mathrm{~cm}$ a $100 \mathrm{~cm}$ foi observada uma textura arenosa, típica dos horizontes E, um horizonte de perda. Dos $100 \mathrm{~cm}$ aos $200 \mathrm{~cm}$ presenciou-se um aumento abrupto do teor de argila, passando de argiloarenosa para argilosa, caracterizando um horizonte de acumulação Bt. 
Aos $200 \mathrm{~cm}$ por meio da tradagem localizou-se o Arenito Caiuá alterado. A S5 foi realizada $12 \mathrm{~m}$ a jusante da S4 (Figura 2).

Na S6 foi avaliado que as transformações, possivelmente associadas aos fluxos hídricos laterais, foram atuantes para a organização da cobertura pedológica. Também foram responsáveis por esculpir a porção do relevo em questão, originando uma espécie de zona de abatimento e mais um degrau arenoso, de 0 a 20 $\mathrm{cm}$, com textura arenosa, sendo denominado de horizonte A (Figura 2). De $20 \mathrm{~cm}$ a $40 \mathrm{~cm}$ a textura continuou a ser arenosa com uma estrutura granular, sendo classificado como horizonte E. De $40 \mathrm{~cm}$ a $200 \mathrm{~cm}$ presenciou-se um aumento de argila significativo, tornando a textura argiloarenosa a arenosa sendo classificado, portanto, como um Bt. A S6 foi realizada 22m a jusante da S5 (Figura 2).

É necessário detalhar que aos $90 \mathrm{~cm}$ houve uma mudança de cor, que tornou-se mais escura devido à proximidade com o lençol freático e ao aumento de argila. De $160 \mathrm{~cm}$ até $200 \mathrm{~cm}$ a porcentagem de argila mostrou-se maior dentre todos os pontos verificados nas tradagens e trincheiras, o solo estava repleto de mosqueamentos também devido à proximidade com a rocha, que encontrava-se bem alterada. Os mosqueamentos derivam da atuação do lençol (zona saturada), hidromorfia, modificando os materiais da encosta, evidência de saturação e aeração, ou seja, de oscilação do lençol ao longo do tempo.

\subsection{Perfil da topossequência}

Por meio da análise detalhada da TR1, TR2, TR3, S1, S2, S3, S4, S5 e S6, foi possível chegar ao resultado final da pesquisa, o perfil da topossequência da cobertura pedológica de um segmento da vertente FEI/UEM (Figura 2). Nas S1, S2, S3, S4, pode-se observar características muito próximas aos solos descritos na TR1, evidenciando a presença do Latossolo Vermelho. Nestes pontos verifica-se a tendência na homogeneização da textura e cor, não se deparando com nenhuma mudança significativa referente às características dos horizontes entre as posições destas sondagens.

A S5 apresenta-se como o local exato do início da ocorrência das transformações laterais, uma nítida mudança do solo se comparado com as quatro primeiras sondagens (S1, S2, S3, S4) e com a TR1, percebe-se aqui que existem ondulações na transição dos solos, possivelmente originadas pela ação do fluxo hídrico subsuperficial lateral. Nesta sondagem, constatou-se a passagem do Argissolo Vermelho para o Latossolo Vermelho a partir de $150 \mathrm{~cm}$, evidenciando a transformação do horizonte.

Provavelmente, os horizontes E e Bt estão realizando um processo de caráter remontante, caracterizando a transformação do horizonte latossólico em argílico, que inicia-se na base da vertente e avança para o topo da mesma, causando a modificação da forma da vertente, com início de uma ligeira concavidade entre os $120 \mathrm{~m}$ de extensão do perfil até o canal fluvial, originando ao mesmo tempo degraus arenosos (Figura 2). 
Menciona-se que os resultados desta pesquisa vão ao encontro dos obtidos nos estudos elaborados por Fernandes Barros (1985) e Castro (1990) em topossequências realizadas em vertentes do planalto ocidental paulista, na cidade de Marília (SP), na pesquisa realizada por Dias Ferreira (1997) em topossequência realizada sobre arenito Piramboia na região de São Pedro (SP) e no trabalho publicado por Lucas et al. (1984) abordando uma topossequência de uma vertente localiza no município de Manaus.

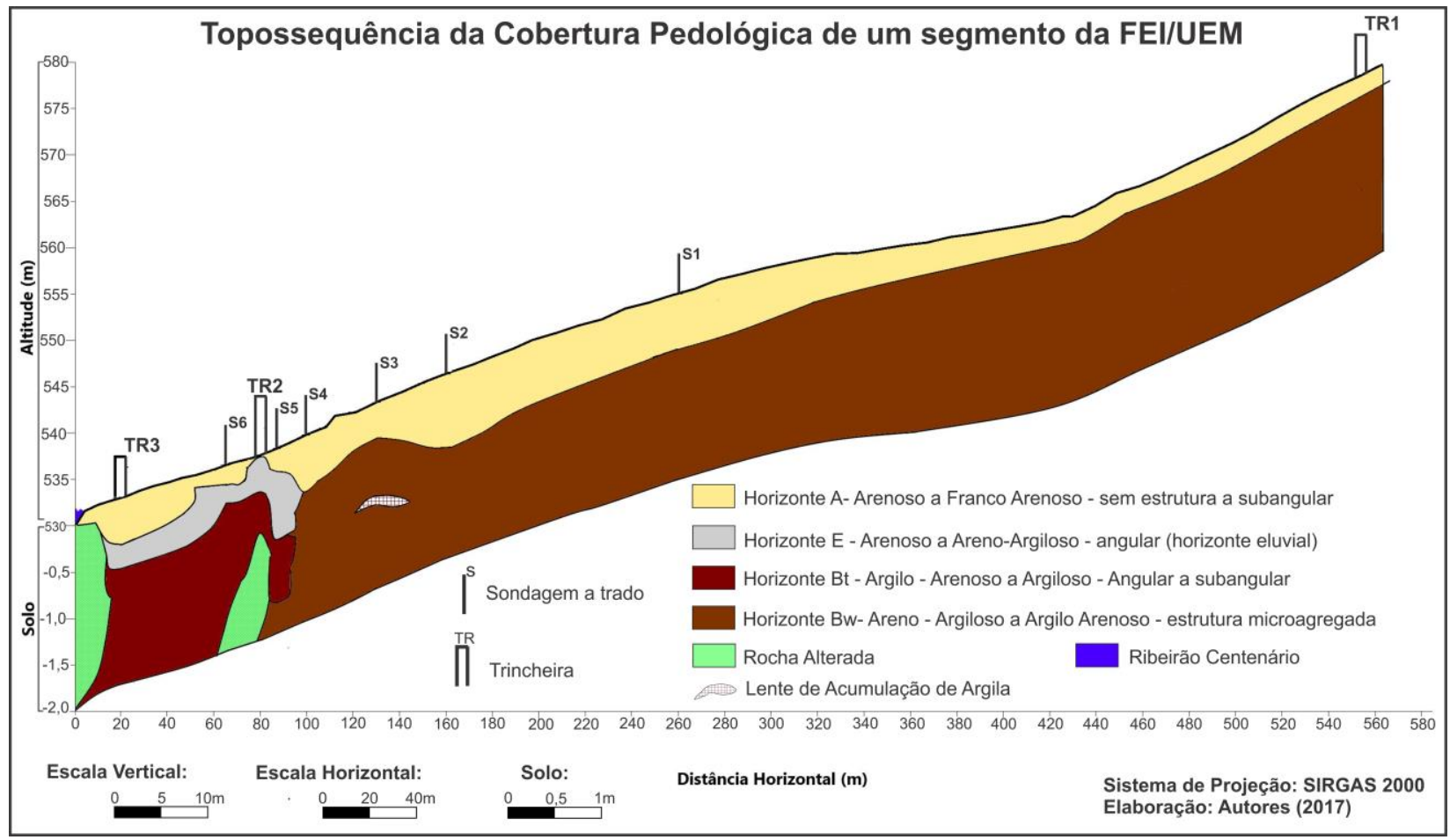

Figura 2: Perfil da topossequência da vertente da FEI/UEM

Resultados, que como no caso da vertente da FEI/UEM apontaram a transformação do horizonte latossólico em argílico por influência dos fluxos hídricos subsuperficiais, que se iniciaram na base da vertente e avançaram remontantemente para o topo da mesma, ocasionando perdas progressivas de argila. O desencadeamento desse processo provavelmente está relacionado à modificação do nível de base local do ribeirão Centenário, que possivelmente acelerou os fluxos internos das soluções na vertente, situação semelhante ao estudo do caso do córrego Invernada divulgado por Fernandes Barros (1985).

Assim como no trabalho de Fernandes Barros (1985), verificou-se no caso desta pesquisa, que na porção mediana superior da pedosequência as perdas de argila acentuaram-se, causando a modificação da forma da vertente, dando início a outro processo de concavização, entre os $340 \mathrm{~m}$ e $440 \mathrm{~m}$ de extensão do perfil (Figura 2), assim como o que ocorreu na base da vertente. 
Portanto, verificou-se que as transformações do sistema pedológico ocasionaram a tendência de concavização da vertente, preservando ao mesmo tempo o paralelismo com os horizontes (Figura 2). Provavelmente, a intensificação do processo acumulará mais água e fará com que as perdas de argila se acentuem, aprofundando a concavidade da base da vertente e a da porção mediana superior, até que as duas concavidades se unam e torne a vertente efetivamente côncava, elaborando ao mesmo tempo a transformação do horizonte latossólico em argílico, como nos apontou Queiroz Neto (2011).

Dessa forma fica evidente que este ponto da vertente (Sondagem 5) apresentou-se como o local exato do início da ocorrência das transformações laterais e da sucessão vertical de solos promovida pelos fluxos hídricos laterais subsuperficiais, responsáveis por originar nítida ondulação verificada na transição dos solos (Figura 2). Na Trincheira 2 (TR2), também presenciou-se maior influência do fluxo hídrico lateral.

Na S6, assim como na TR3 avaliou-se que as transformações laterais também eram atuantes como na S5, originando uma espécie de zona de abatimento. É válido frisar novamente que a leve concavidade originada na baixa vertente acentua todo o processo das transformações pelo acúmulo de água em alguns pontos, formando degraus arenosos com gênese associada às atividades geoquímicas.

\section{Considerações Finais}

Verificou-se por meio desta pesquisa que a vertente em questão representa um sistema pedológico em transformação, sob influência dos fluxos hídricos laterais e verticais, com possível alteração do nível de base local do ribeirão Centenário. Tais fatores impuseram modificações na cor, textura, estrutura, porosidade entre outros atributos físico-químicos dos solos que podem ser relacionados aos fluxos hídricos responsáveis pela realização das atividades geoquímicas, como relata Queiroz Neto (2011). $\mathrm{Na}$ interpretação dos autores, a erosão geoquímica apresentou-se como responsável pelas perdas de argila e pela configuração da encosta, pois a cobertura pedológica transformada manteve-se paralela a vertente, indicando que evoluíram conjuntamente. A leve concavidade originada na baixa vertente acentua todo o processo, formando degraus arenosos, o que é possível visualizar no perfil da topossequência, principalmente relativo ao horizonte A superficial e E do Argissolo Vermelho. Por estas evidências tornase possível afirmar que a vertente em questão representa um sistema pedológico em transformação.

Os fluxos hídricos verticais são predominantes na organização da cobertura pedológica na alta e média vertente (TR1, S1, S2, S3 e S4), já os fluxos laterais se tornam mais atuantes na média baixa (S5 e TR2) e na baixa vertente (S6 e TR3), originando ondulações nos horizontes de solo devido às atividades geoquímicas.

A pesquisa apresentou-se capaz de demonstrar a influência que as ações pedogenéticas podem exercer na elaboração das formas do relevo/vertente, através do exemplo de tendência de concavização verificada na 
vertente FEI/UEM, por meio de transformações possivelmente impulsionadas por influência dos fluxos hídricos subsuperficiais laterais e verticais. Estes fluxos ocasionaram perdas progressivas de argila e aceleraram os fluxos internos das soluções na vertente por meio da atuação de atividades geoquímicas que, ao mesmo tempo, esculpiram novas formas do relevo (concavização do perfil).

\section{Bibliografia}

BIGARELLA, J. J.; MAZUCHOWSKI, J. Z. Visão Integrada da problemática da erosão. In: SIMPÓSIO NACIONAL DE CONTROLE DA EROSÃO, 3, 1985, Maringá. Livro Guia, Curitiba, Associação Brasileira de Geologia de Engenharia, 1985. 329p.

BOULET, R.; CHAUVEL, A.; HUMBEL, F. X.; LUCAS, Y. Analyse structurale et pédologie. I Prise em compte de l'organization bidimensionnelle de la couverture pédológique: lês études de toposéquences et leurs principaux apports à la connaissance dês sols. Cahiers O.R.S.T.O.M., sér. Pédolologie, v. 19, n. 4, p. 309-322, 1982.

CASTRO, S. S. Sistemas de transformação pedológica em Marília: B latossólicos e B texturais. 1990. 274f. Tese (Doutorado em Geografia Física) - FF C H, USP, São Paulo.

DIAS FERREIRA, R. P. Solos e morfogênese em São Pedro, SP. 1997. 157. Tese (Doutorado em Geografia Física) - Dep. Geografia, FFLCH, USP, São Paulo.

EMBRAPA. Manual de descrição e coleta de solo no campo. $5^{\text {a }}$ ed. Viçosa: Sociedade Brasileira de Ciência de Solo, 2005.

ESPINDOLA, C. R. A pedologia e a evolução das paisagens. Revista do Instituto Geológico, São Paulo, v.31, n.1/2, p.67-92, 2010.

FERNANDES BARROS, O. N. Análise estrutural e cartografia detalhada de solos em Marília/SP: ensaio metodológico. 1985. 146f. Dissertação (Mestrado em Geografia Física) - Dep. Geografia, FFLCH, USP, São Paulo

GASPARETTO, N. L; SOUZA, M. L. Contexto geológico-geotécnico da Formação Caiuá no Terceiro Planalto Paranaense - PR. $1^{\text {a }}$ ed. Maringá: ENGEOPAR, 2003.

JENNY, H. Factors of soil formation. New York: MaGraw-Hill Book Inc., 1941.

LUCAS, Y.; CHAUVEL, A.; BOULET, R.; RANZANI, G.; SCATOLINI, F. Transição latossolos - podzois sobre Formação Barreiras na região de Manaus. Rev. Bras. Ci. Solo, v. 8, p. 325- 335, 1984.

MILNE, G. Some suggested units of classification and mapping particularly for East Africain soils. Soil Research, v. n.3, p. 183-198, 1935. 
MUNSELL, A. H. A color notation. 14ª ed. Baltimore: Macbeth, A division of Kollmorgen Coporation, 1981.

QUEIROZ NETO, J. P. Relações entre as vertentes e os solos: revisão de conceitos. Revista Brasileira de Geomorfologia, v. 12, n.3, p. 15-24, 2011.

TRICART, J. As relações entre a morfogênese e a pedogênese. Notícia Geomorfológica, v.8, n. 15, p. 5-18, 1968. 